\title{
Modelling Sustainable Entrepreneurship in the Covid-19 Era
}

\section{José Maros Bustos-Aguayo ${ }^{1}$, Gilberto Bermúdez-Ruíz², Margarita Juarez- Najera $^{3}$, Francisco Espinoza-Morales ${ }^{4}$, Cruz García-Lirios ${ }^{1 *}$, Javier Carreón- Guillén $^{1}$, Jorge Hernandez-Valdes ${ }^{1}$, Francisco Ruben Sandoval-Vazquez ${ }^{5}$}

\author{
${ }^{1}$ Mexico University, MEXICO \\ ${ }^{2}$ Anahuac University, MEXICO \\ ${ }^{3}$ Metropolitan University, MEXICO \\ ${ }^{4}$ Sonora University, MEXICO \\ ${ }^{5}$ Morelos University, MEXICO \\ *Corresponding Author
}

DOI: https://doi.org/10.30880/jstard.2021.03.02.004

Received 22 June 2021; Accepted 25 August 2021; Available online 15 December 2021

\begin{abstract}
Anthropocentrism and ecoperiphery are two foundations that the present work used to specify a model for the study of sustainable local entrepreneurship. The differences between beliefs of scarcity and abundance of resources generate values, skills and knowledge that guide the undertaking of conservation or consumption of natural resources. A review of the Human Development problem, the theoretical and conceptual frameworks, as well as the most recent findings about social entrepreneurship allowed the specification of the relationships between the factors reviewed for discussion. Given that the documentary research allowed the discussion of two options for social entrepreneurship, one oriented to the conservation of nature and the other oriented to the exploitation of natural resources and the consumerism of public services, it was possible to anticipate study scenarios in those that the analysis of local and sustainable would start with perceptions, beliefs, values, knowledge and skills that make it possible to explain austere or consumerist lifestyles. The objective of this work was to specify a model for the study of sustainable entrepreneurship considering a review of the literature from 2019 to 2021. A cross-sectional and psychometric work was carried out with a sample of 450 coffee growers. A structure of three factors was found that explained $27 \%$ of the total variance, although the contrast of the model is recommended in other scenarios and samples.
\end{abstract}

Keywords: Development, entrepreneurship, sustainability, anthropocentrism, ecoperiferism

\section{Introduction}

Until April 2021, the pandemic has caused the death of three million in the world and 500 in Mexico. In this scenario, mitigation policies have focused on confinement and social distancing, discarding the micro-financing of micro, small and medium enterprises as a factor for economic reactivation. In this sense, social commitment has resulted in the optimization of resources rather than innovation and processes. In this way, the study of entrepreneurship has been oriented towards social responsibility that involves taking advantage of opportunities in a sustainable way. This is the case of the promotion of ecological products and processes that involve a greater redistribution of profits. It is a knowledge management, production and transfer system oriented towards the conservation of natural resources, but in a pandemic scenario, resource grabbing limits optimization and social responsibility decisions. 
This is how the objective of this work is to specify a model for the study of sustainable entrepreneurship, considering its dimensions of opportunism, optimization and innovation as a social response to the policies of confinement and social distancing that limit economic reactivation, but encourage optimization and process innovation.

What are the dimensions of responsible entrepreneurship with care for the environment, considering the pandemic as a risk event limiting economic reactivation?

The premise that guides this work suggests that the pandemic is a risk event because it reduces the expectation of measurement and control of the rulers and the ruled in the face of the effects of contagion, disease and death. In this contingent scenario, political actors try to limit the movement of people, the interaction between and trade to mitigate the pandemic, but confinement and social distancing have turned out to be a counterproductive strategy to entrepreneurship focused on microfinance. Given the shortage of micro credits, civil society is organized around the optimization of resources, considering remittance transfers, as well as solidarity cooperation. It is a local undertaking that becomes sustainable as it is oriented towards process innovation such as the management, production and transfer of knowledge in the reuse of products or recycling.

\section{Literature Review}

\subsection{Theory of Sustainable Entrepreneurship}

Entrepreneurship is a global phenomenon that consists of the public management of knowledge for its dissemination among political actors, economic agents and social talents in order to preserve natural resources for the Sustainable Development of representations, habitus, fields, capitals and capacities of future generations. Precisely, the objective of this work is to expose the conceptual relationships between the dimensions of entrepreneurship in a Mexican town. To carry out these purposes, a theoretical and empirical review was carried out in order to discuss the concepts and findings circumscribed to entrepreneurship. This will open the discussion around the relationship between the State, transnational corporations, SMEs and communities in situations of scarcity and inequity in the distribution of resources. The entrepreneurship supposed representations, habitus, fields and capitals around the production, marketing and business training. In a certain sense, objectification and anchoring, essential processes of social representations, explain the transformation of knowledge and knowledge into common sense, more precisely, touristic from which the logic of supply and demand fades into affects or feelings about direct time and money to coffee production.

However, not only knowledge is disrupted by entrepreneurial forces, but also adjusted to the local ecotourism dynamics. In this sense, the discourse among other elements is the means to build predispositions around coffee growing. Thus, through social representations, coffee growing is transformed into discursive habitus from which local conventions are supported in reference to global conventions, since micro-enterprises, being linked to transnational companies, adopt organizational forms and discourses to promote entrepreneurial spirit in inhabitants of "magical towns" as in the case of the Huasteca region in Xilitla, San Luis Potosí, Mexico. It is a process in which symbols, meanings and meanings are categorized into images that impact personal interpretation and action, although this process is disseminated to groups and organizations related to coffee. This makes possible the social distinction of an entrepreneurial sector in reference to the community, but even in reference to the other agricultural groups of the Huasteca region.

At the discursive level, it is not only possible to differentiate symbols or meanings in their temporal or spatial spheres, but also to anticipate the diversity of expectations that are generated after a business activity has become a hallmark of a community in clear allusion to industry, commerce, tourism or poverty, marginalization, vulnerability or exclusion. Such dimensions are condensed into propensity or aversion to the future since while social representations relate to the past and the future, they generate risk predispositions around which a sowing and harvest is planned. In other words, the representation of coffee growing seems to be circumscribed to preferences, actions, feelings or thoughts, which constitute discourses that delimit fields of expectations and generate relationships of cooperation and trust.

Theoretical frameworks explained the interweaving of coffee growing in the speeches of producers and traders. The Theory of Social Representations, being a process of communication of innovations regarding coffee growing, infiltrates the symbols and meanings that microentrepreneurs construct. Once these have infiltrated images and words, they are now recovered as a repertoire of knowledge regarding the always or harvest of coffee.

If a representation links coffee growing with other personal or community needs, then it implies provisions that facilitate the objectification or anchoring of information related to planting, harvest, climate, pests, prices and quotes. If such provisions have been transferred from generation to generation then a longitudinal study would account for the representations, objectification and anchoring, as well as their habitus, inherited or acquired, throughout a relatively transitory period in which the community went from being migrant to microentrepreneur. Thus the theory of the habitus Discourse focuses efforts explanation in those symbols that can be derived symbols, grouped and significance showing at the same time a way of thinking, acting and feeling that would distinguish Xilitla other indigenous peoples or magical dedicated to coffee growing. For the purposes of this study, differentiating communities is the first link to infer 
the process through which a group of migrants became microentrepreneurs. In this sense, the Theory of Power Fields maintains that the conflicts derived from the asymmetric distribution of inputs for coffee growing is the engine of the changes that are coming in the production and commercialization of coffee in the micro-region.

However, such a transformation seems to be more discursive and that while migrants from Xilitla return, trade groups the task of undertaking new projects and business plans involving di are given of the people as a place of tourism and recreation than of coffee production and sale. At the level of symbols, it is necessary to understand the discursive relationships between those who create jobs and those who diversify them with the diffusion of community innovations such as ecotourism, organic production, handicrafts and typical food. Such a process of diversification and interweaving of coffee growing is focused on the formation of collaborative networks, not just discursive. These are processes of trust in which the cooperation between the families of coffee growers makes their analysis feasible as social capitals in which knowledge is no longer a matter of management, but of representation, habitus and empowerment.

In this way, Xilitla is assumed to be an economically prosperous entity because it is anchored in discourses that deal with entrepreneurship, commerce and progress. That is, at least the community no longer shows symptoms of discursive or economic impoverishment. The people who live in this micro region assume themselves as responsible for their own destiny and accordingly, carry out actions motivated by the social differentiation that being a migrant, merchant, coffee farmer or micro-entrepreneur implies.

However, the process would be incomplete if we did not recognize the opportunities in line with the capacities and responsibilities of the inhabitants of Xilitla towards their future generations and other social capital networks that act in favor of the progress of the community or at least the distancing with poverty. The Theory of Economic Capabilities in line with the freedoms of choice for the covering of the social fabric in terms of employment, health and education, assumes that individuals are agents of knowledge and management whose capacities allow the dissemination of responsibilities towards the groups in those who are immersed. It is precisely at this point where symbols and meanings regarding coffee growing are linked to scenarios of collaboration and knowledge transfer that allow traders to enter a local market. It is here where the knowledge that makes possible the differentiation of coffee growing in planting, harvesting, refining, packaging, logistics, distribution, preparation and sale seems to emerge. The new generations of coffee growers have not only objectified or anchored knowledge but have also assumed it as part of their lifestyles and discursive modes.

Faced with the environmental problems of droughts or floods, the social capital networks in Xilitla respond by organizing cultivation in diversified stages but confined to the achievement of goals that guarantee the productive cycle. Furthermore, the production process is complemented with the management and promotion of coffee growing in other locations in the region and beyond it as a tourist entity. This is the key to economic success and prosperity in Xilitla, of which remittances continue to be a fundamental part of the economic dynamics, but it is symbolic capital that drives social, political and economic relations. The culture of entrepreneurship or the entrepreneurial spirit of Xilitla undermines poverty and encourages business and labor capacities to stabilize the representations, habitus, fields and capitals related to coffee growing.

\subsection{Models of Sustainable Entrepreneurship}

The study area has a Human Development level close to 0.80 in the corresponding United Nations index. However, this index is composed of the items of education, employment and health related to opportunities and capacities that are linked to the habitus of entrepreneurship, but linked to values, knowledge and anthropocentric skills that justify Human Development from the exploitation of natural resources. In this sense, anthropocentrism emerges from school competencies indicated by three levels of literacy, illiteracy and functional illiteracy. In this way, literacy is close to anthropocentrism insofar as it develops beliefs of scarcity of resources that science and technology must assess to guarantee the opportunities and capacities of future generations. In addition, the State, from a literate anthropocentric vision, is the leader of Sustainable Local Human Development, since literate participation implies the emergence of consumerist and austere lifestyles to the extent that public policies regulate the rates of public services.

In the case of the study municipality, its degree of literacy $(60 \%)$ in the population aged 6 to 24 is lower than that of the illiterate population $(80 \%)$. In other words, literacy would be related to anthropocentric beliefs, while ecoperipheral visions would be related to local illiteracy. Compared to anthropocentric beliefs, ecoperipherals consist of respect, fear and mystification of nature. It is often indicated by high rates of perception of risk, uncertainty, and insecurity that correlate with beliefs about the abundance of natural resources. In this way, illiteracy, related to ecoperipheral beliefs, would correlate with a high life expectancy, not only due to the consumption of local and natural products, but also due to risk-averse lifestyles. In contrast, a low life expectancy implies a propensity for risks that support anthropocentric beliefs. In the study demarcation, life expectancy is 74 years, but if it is taken into account that the deterioration in the quality of life begins ten years earlier, then it is probable that anthropocentrism and risk propensity are factors of styles in which consumerism increases the probability of diseases related to the heart, diabetes or hypertension.

However, if we contrast the life expectancy of the Federal District with that of San Luis Potosí, then it will be possible to notice a contradiction since while life expectancy exceeds 78 years in the capital of Mexico, the difference 
with respect to life expectancy in the study demarcation is five years. Indeed, life expectancy seems to indicate that urban anthropocentrism guarantees a higher quality of life than rural ecoperipherism, however, $4 \%$ of the local unemployment rate is less than $7 \%$ of the unemployment rate of the Federal District. The contrast between the indices seems to show that Sustainable Local Human Development depends on education, life expectancy and employment whenever it comes to urban entities. In reference to rural or semi-urban demarcations, anthropocentric and ecoperipheral beliefs could explain the differences at least with respect to the capital of the country.

\subsection{Studies of Sustainable Entrepreneurship}

By virtue of the fact that social entrepreneurship depends on the socio-political and environmental environment, by defining itself as a system of initiatives oriented to Human Development in its educational, health and labor areas, as well as the propensity to be locally sustainable, the Theory of Social Entrepreneurship includes four factors that explain the interrelationship between the indicators. The concept of habitus refers to a set of anchored dispositions, if one wants to relate to social representations, in the nucleus or centrality of a context. As a system of dispositions, they are indicated by associations between people, behaviors, feelings, opportunities, capacities, responsibilities or freedoms. However, its psychological symptoms are only part of sociological dimensions from which it is possible to notice differences between groups, communities, societies, cultures or generations. These are relationships between structures, beliefs, norms and values, which can be found in organizations or institutions, but since they are not exclusive to such contexts, it opens up the possibility that habitus are themselves contexts of settings. In such a process, the discursive habitus is linked to practices that enhance the differences between individuals since they can act under the same context, but the meaning or resignification of spaces, objects or people is different. This is so because habitus are the product of asymmetries, discrepancies, controversies, disagreements or tensions that may be of short duration, although they may extend given the magnitude of the conflict and, above all, the influence of the context. The truth is that a context impacts actions, feelings, perceptions and thoughts in a more lasting way because it infiltrates the structure of discursive skills and by being naturalized, following the discourse of social representations, they are no longer only in the periphery, otherwise they have been incorporated into the central nucleus. In other words, habitus are the result of the penetration of the context in the cultural repertoire of individuals and, having infiltrated the concepts of defense, they have become familiar with the central elements.

Habitus are a consequence of context in the form of a schema and organization of symbols. This duality makes it more feasible to recognize the complexity of the context since habitus are its indicators. It is a context, in terms of human life, short since they are inherited and learned structures in the first years of life. Such process reveals a socio- historical dimension of habitus and therefore another socio-political dimension consisting of the socialization of the schemes and structuring of the dispositions which, if it were a dialectical process, but it is not because it is rather the influence of the context in the personal schemes.

Like the social representations that defend themselves from the emergence of other symbols, the habitus will not repair to counteract the influence of other habitus while defining the actions to be followed according to the contexts to be deterred, since new events would imply a diversity of responses, but such Resources are rather homogeneous thanks to the fact that each person incorporated a system of symbols, meanings and meanings that differentiate them from other people or from themselves under similar or diametrically different circumstances. In short, habitus come from the past located in childhood, but also when acquired and not only inherited, it supposes disposition is emergent that indicate the penetration of the context in the structure of dispositions.

In the case of migration and entrepreneurship, the habitus explain the process by which a society passes traders ejectors. This, of course, goes beyond the influence of the context in the communities or individuals, it supposes the incidence of public policies related to tourism since the Huasteca community of Xilitla obtains its income from the promotion of its ecotourism space, mountainous areas and forested, and its s uses and customs coffee. In this way, the habitus of the community past explain migration since, in their eagerness to build a heritage, the residents of Xilitla had to seek employment outside their territory. Once a heritage was built, the former migrants returned to their community to establish the discourses acquired abroad and that it is possible to identify as an entrepreneurial process if it is assumed that for this purpose a climate of trust, commitment and satisfaction was generated. In other words, the new generations of entrepreneurs are the result of a generation that inherited a migratory habitus and / or transformed into an entrepreneurial habit, but such a process must have occurred in a context in which business development policies were strategically oriented to tourism and their derivatives. Thus, the socio- historical premise of the habitus is fulfilled according to which a situation is the result of a structure, although not entirely influenced, if it has been upset in its foundations since the community of Xilitla is now entrepreneurial. The resurfacing of its streets, the remodeling of its buildings, the relocation of its waste, the financing of its trade and investment in hotel, restaurant and road infrastructure suggest that the community is committed to tourism as an alternative for progress and prosperity, but there is a coffee sector that has managed to insert itself into the migrant habitus and now into the new entrepreneurial dynamics since it employs other workers from surrounding towns and markets with other groups of coffee growers in the Huasteca region. Although it is true that the migrant and business habitus are discourses related to the search for opportunities, capacities and responsibilities, it is striking that in the case of the migrant habitus, emotions predominate over the actions or deliberations that correspond to the entrepreneurial habitus. In other words, the differentiation 
between one habitus and the other is that the economic situation prevented the implementation of innovations and directed actions towards migration, while in the current situation, the minimum factors for carrying out projects that are financed by the State seem to be combined. through the secretary of tourism and labor, but which are accepted and developed by the community.

However, while an entrepreneurial habitus was forged, resources were redistributed, mainly the speeches and their symbolic assets that gave rise to power scenarios without which it would be impossible to explain the differences between day laborers and coffee growers, authorities and citizens, politicians and merchants.

\subsection{Modelling of Sustainable Entrepreneurship}

Studies related to social entrepreneurship show that entrepreneurial capacities are determined by discourses, relationships, productions, acquisitions and representations alluding to initiatives that, supported by enough levels of education, employment and health, generate sustainable local initiatives. It is research that are based on the assumption that the opportunities offered by the state have a correspondence with values, skills and knowledge that will be aimed at the mastery of nature (anthropocentric) or, to the mystification of this (ecoperiferismo). In the first case, the consumerism of public resources and services is an indicator that contrasts with austerity, the main indicator of eco peripheralism.

The entrepreneurial spirit, whether inherited in the place of origin or acquired in the migrant's place of stay, supposes a process that would culminate in life satisfaction as remuneration increases or opportunities diversify. That is, life satisfaction seems to have a link with the entrepreneurial spirit in terms of the search for utility, profit and benefit from a systematic activity that implies a commitment to an organization. That is why that in contexts of uncertainty the Mobbing inhibits life satisfaction and significance entrepreneurship and the obstacles posed by relations task are undermined by $\mathrm{h}$ relations Oumana. Indeed, if the relationships between colleagues overlap with the objectives of the group, then in the entrepreneurial spirit dimensions of a resilient order emerge in which the individual will develop coping strategies in the face of the inconveniences of working under a climate of tension.

In such a scenario, the entrepreneurial spirit correlates with transformational leadership styles in which each of its symptoms are sustained by specific innovation actions that disrupt other corrective, avoidant, or motivating styles. In this sense, human relationships between leaders and subordinates seem to influence individual rather than collective or group entrepreneurship by the simple fact of including egocentric rather than altruistic values. There are also differences between men and women with respect to stressful situations in which the entrepreneurial spirit is inhibited more in male groups than in female groups. Apparently, the relationships that are established between men facilitate coping with noise. It is in male groups where a climate of trust is developed that is more linked to life satisfaction, the main indicator of the entrepreneurial spirit. As the tasks involve greater coordination, collaboration between workers increases, but a reduction in it is closer to frustration, although this implies the innovation of ideas as another symptom of entrepreneurship.

However, the agreements between leaders seem to affect more the work dynamics between subordinates and even motivate them to carry out strategies to adjust their actions to the decisions of the high command. This means that the entrepreneurial spirit would also be motivated by the dynamics of decisions and their effects on the job stability of employees. If job satisfaction is the result of a climate of positive tasks and relationships, then the entrepreneurial spirit would have two dimensions. The first dimension is the product of favorable contexts for the formation of groups, and the consecution objectives while the second would be the result of a series of barriers and obstacles from the creativity and innovation is encouraged.

However, if the results deviate from the established goals, then a series of conflicts arise that foresee the change of paradigm in interpersonal relationships and the way in which teamwork is carried out. In other cases, the entrepreneurial spirit, by spuriously correlating with life satisfaction, denotes other factors that would be influencing it since it would be rather indicated by impersonal factors and close to stress levels that, far from reducing entrepreneurship, accrue it as a alternative to organizational contingencies. In reference to performance and productivity, both dimensions of the entrepreneurial spirit announce the incorporation of lifestyles that develop within organizations as a response to the absence of leadership. This means that when communication channels are blocked, then employees adapt to a production pattern that leads them to achieve their goals. This is so because in the workplace the economic stability of talents is involved who, in the face of the onslaught of problems inherent to senior management or recognition crisis, develop skills, knowledge and values oriented towards the innovation of processes rather than control quality. Entrepreneurship is under the context of conflict a construction of the needs, expectations and competencies of employees.

However, entrepreneurship also underlies the sense of community and identity rooted around a to region, locality or space. In other words, the workers residing in the areas surrounding the organizations are willing to accept the working conditions if jobs are generated that favor the community, even if the company takes the greatest of the profits. It is identity processes that involve entrepreneurship, but also competition for resources. In both cases, organizational commitment is revealed as a relevant factor by influencing performance, satisfaction and skills. In those localities where transnationals implemented knowledge management systems and transferred a production model to the 
community, the labor commitment intensified. That is, shared knowledge was generated, but in cases where the knowledge was the result of transnational technology and local community participation, the commitment also increased substantially. The same processes were observed in those cases in which transnational companies implemented knowledge management models in local small and medium-sized companies. Work commitment seems to have been the main determinant of entrepreneurship if trust and innovation were correlated with both variables. Based on these reviews, it is possible to affirm that entrepreneurship has as essential indicators commitment, trust, innovation, cooperation and resilience; By relating to local culture, community customs and practices as well as regional identity, the entrepreneurial spirit substantially increased its values of life satisfaction.

However, strategic planning based on international quality standards has had an impact on higher productivity and intensification of competitiveness more than hybrid models and alliances between transnationals and SMEs. The state of the question warns of the emergence of entrepreneurship in local contexts from which strategic alliances are developed at the regional and local level in which the communities adopt management, production, logistics and sales systems disseminated by transnational corporations. through SMEs or micro-enterprises. In a context in which business development policies are intensifying, the entrepreneurial spirit seems to be a response from the communities that were previously migrants and that are now scenarios of federal and local investment that led them into a dynamic on which they built representations, habitus, fields, capitals and capacities oriented to local development.

\subsection{Specification a Model of Sustainable Entrepreneurship}

By social entrepreneurship is considered a capacity, the factors that explain it are also capacities that, when interrelated, build an anthropocentric or ecoperipheral system. In the anthropocentric system, entrepreneurial capacities are the result of the productivity implied by discourses of domination of nature and cooperation for this purpose, but they also imply the acquisition and inheritance of lifestyles that, due to their degree of consumerism, reveal representations of the scarcity of resources and, consequently, the formation of capacities that allow their hoarding or the exclusion of communities with which resources are shared.

On the contrary, the entrepreneurship considered ecoperipheral is the product of trust and cooperation between communities that develop skills and knowledge of respect and conservation of natural resources, but also this ecoperipheral entrepreneurship is based on beliefs of abundance of the natural resources and therefore of representations of incommensurability and unpredictability of natural phenomena and environmental catastrophes. That is, in social entrepreneurship, anthropocentric and ecoperipheral beliefs coexist that are generated by the scarcity or abundance of resources, altruistic and egocentric values, knowledge and knowledge, as well as conservation or consumerism skills.

\section{Research Methodology}

Since the pandemic has long-term effects, it was decided to observe the responses of the respondents in a short period of time, considering their exposure to contagion, as well as their ventilation stay, factors that have not been addressed and therefore oriented the work towards the exploration of the dimensions and entrepreneurship, as well as their level of social responsibility to consider it sustainable. In this way, the recording and observation of the indicators suppose a psychometric investigation.

100 entrepreneurs $\left(\mathrm{M}=34.32 \mathrm{SD}=2.31\right.$ of age and $\mathrm{M}=9^{\prime} 873,21 \mathrm{SD}=152.12$ pesos per month $)$ from central Mexico were surveyed, considering their change of business before and during the pandemic, as well as their contacts with migrants and common employees.

The Sustainable Entrepreneurship Scale was used, which includes three dimensions related to optimizing responsibility ("Covid 19 forced me to prevent infections with limited resources"), innovative conservation ("Covid 19 forced me to protect my children's assets") and ecological opportunism ("Covid 19 opened my eyes to recycling"). All items include five response options ranging from $0=$ "not at all agree" to $5=$ "Fairly agree".

Invitations were sent to a total of 450 micro-entrepreneurs belonging to a local association of coffee growers. Around 130 answered, but only 100 were considered, considering that they met the profile of opportunistic entrepreneurs, optimizers and innovators, as well as contacts with migrant capital and organized employees in the production, distribution and sale of coffee. Respondents were informed in writing about the guarantees of confidentiality and anonymity of their responses, the researcher responsible for the project and the collaborators, providing the data of the researchers' university affiliation. The fact that the project did not include any payment for participating in it was emphasized, as well as the null subsidy from authorities and companies dedicated to the sale of coffee. A link was sent www.atn.es.tl where the respondents could access the instrument.

The data were processed in the statistical analysis package for social sciences, version 23.0, considering the requirements of normality, homoscedasticity, linearity, adequacy and sphericity. Validity was estimated with the principal axe's method with promax rotation, as well as confirmation with a structural equation model. 


\section{Result}

The values of the distribution of responses to the instrument reached essential minimum levels (see Table 1). The results show the consistency of the reagents in different scenarios and samples if the scale is applied at other times of the pandemic, as well as the prevalence of three factors related to opportunism, optimization and innovation.

Table 1 - Descriptive instrument

\begin{tabular}{lllllll}
\hline R & M & SD & A & F1 & F2 & F3 \\
\hline r1 & 4,21 & 1,89 &, 718 &, 678 & & \\
\hline r2 & 4,90 & 1,02 &, 793 &, 659 & & \\
\hline r3 & 4,12 & 1,43 &, 706 &, 632 & & \\
\hline r4 & 4,67 & 1,54 &, 782 &, 568 & & \\
\hline r5 & 4,31 & 1,21 &, 704 &, 405 & & \\
\hline r6 & 4,30 & 1,36 &, 795 &, 657 & & \\
\hline r7 & 4,65 & 1,78 &, 735 &, 435 & & \\
\hline r8 & 4,32 & 1,36 &, 762 &, 651 & & \\
\hline r9 & 4,76 & 1,95 &, 705 & &, 516 & \\
\hline r10 & 4,10 & 1,50 &, 794 & &, 403 & \\
\hline r11 & 4,11 & 1,52 &, 786 & &, 632 & \\
\hline r12 & 4,80 & 1,69 &, 773 & &, 541 & \\
\hline r13 & 4,31 & 1,74 &, 761 & &, 403 & \\
\hline r14 & 4,67 & 1,80 &, 702 & & .631 & \\
\hline r15 & 4,59 & 1,84 &, 719 & &, 602 & \\
\hline r16 & 4,32 & 1,94 &, 756 & &, 653 & \\
\hline r17 & 4,36 & 1,57 &, 784 & & &, 546 \\
\hline r18 & 4,28 & 1,73 &, 790 & & &, 632 \\
\hline r19 & 4,59 & 1,03 &, 776 & & &, 436 \\
\hline r20 & 4,04 & 1,09 &, 753 & & &, 650 \\
\hline r21 & 4,84 & 1,38 &, 718 & & &, 512 \\
\hline r22 & 4,36 & 1,59 &, 704 & & &, 567 \\
\hline r23 & 4,80 & 1,21 &, 752 & & &, 543 \\
\hline r24 & 4,68 & 1,38 &, 740 & & &, 435 \\
\hline & & & & &
\end{tabular}

Note: Elaborated with data study. $\mathrm{R}=$ Reactive, $\mathrm{M}=$ Mean, $\mathrm{SD}=$ Standard Deviation, $\mathrm{A}=$ Alpha excluded value item. Adequation $(\mathrm{KMO}=, 762)$, Sphericity $[\chi 2=14,32(16 \mathrm{df}) \mathrm{p}<, 05]$ Method: Principal Axes, Rotation: Proma. F1 = Oportunism (14\% total variance explained and alpha with ,780), F2 = Optimization (10\% total variance explained and alpha with ,756), F3 = Innovation (3\% total variance explained and alpha with ,739). All items include five response options ranging from $0=$ "not at all agree" to $5=$ "Fairly agree".

Having established the three factors that explained $27 \%$ of the total variance, we proceeded to estimate the structure of relationships between factors that anticipate explanatory trajectories of entrepreneurship as a threedimensional phenomenon in a pandemic context (see Table 2).

Table 2 - Relations between factors

\begin{tabular}{lllllllll}
\hline & M & SD & F1 & F2 & F3 & F1 & F2 & F3 \\
\hline F1 & 28,12 & 16,28 & 1,000 & & & 1,890 &, 671 &, 602 \\
\hline F2 & 28,56 & 15,90 &, $651 *$ & 1,000 & & & 1,768 &, 598 \\
\hline F3 & 25,21 & 17,02 &, $592 * *$ &, $620 * * *$ & 1,000 & & & 1,956 \\
\hline
\end{tabular}

Note: elaborated with data study; $\mathrm{M}=$ Mean, $\mathrm{SD}=$ Standard Deviation, $\mathrm{F} 1=$ Oportunism, F2 = Optimization, F3 = Innovation; * $\mathrm{p}<, 01 ; * * \mathrm{p}<, 001 ; * * * \mathrm{p}<, 0001$

In order to observe the structure of trajectories and relationships between the three factors with respect to their indicators, the structural equations model was estimated (see Figure 1). 


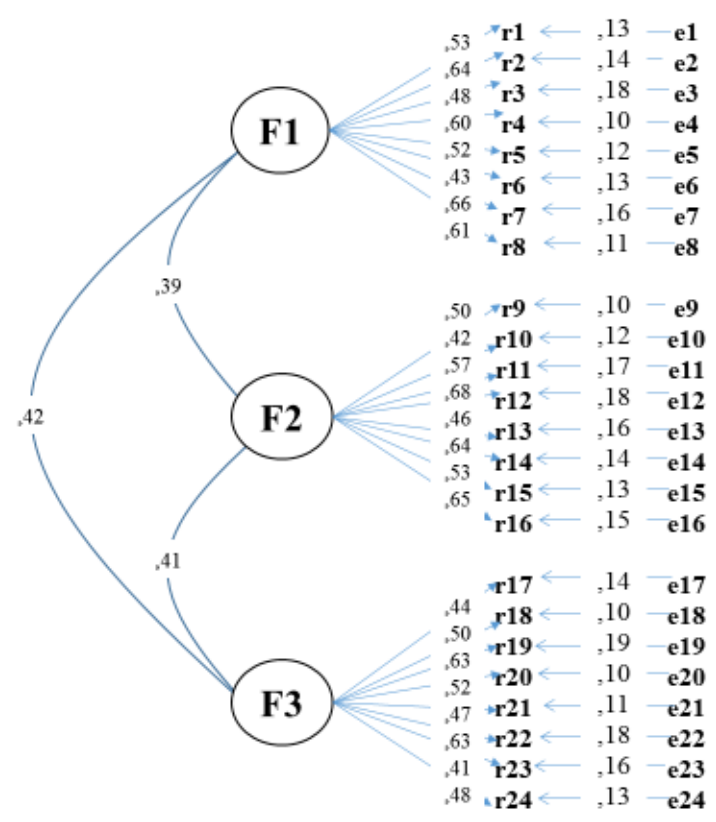

Fig. 1 - Structural equation modelling

Note: elaborated with data study; $\mathrm{M}=$ Mean, $\mathrm{SD}=$ Standard Deviation, $\mathrm{F} 1=$ Oportunism, $\mathrm{F} 2=$ Optimization, $\mathrm{F} 3=$ Innovation; $\mathrm{e}=$ Error measurement indicator, $\mathrm{d}=$ disturbance measurement factor

The adjustment and residual values $\{\chi 2=13,24(15 \mathrm{df}) \mathrm{p}>, 05 ; \mathrm{CFI}=, 997$; GFI $=, 995$; RMSEA $=, 0008\}$ suggest the non-rejection of the null hypothesis relative to the significant differences between the dimensions reported in the literature with respect to the structure observed in the present work.

\section{Discussion}

The entrepreneurship in a context of migration and commercialization of natural resources in Xilitla is determined by representations, habitus, field and capital from which indicators of trust, commitment, innovation, management, leadership, competitiveness and performance spread. A review of studies on the determinants of entrepreneurship confirms assumptions around which resilience is an inherent factor in its emergence when stressful dynamics are gestated in which exhaustion, depersonalization or frustration emerge as its main symptoms. However, entrepreneurship underlies contexts of roots and identity which are used by transnationals when establishing alliances with SMEs and local cooperatives. In this sense, entrepreneurial capacities acquire new production, distribution and sale strategies taking advantage of community relations networks.

The social representations of global brands seem to form habitus of consumption from which discursive fields of power are built that give value to transnational products and services through local organizations. In this process, the models of strategic alliances are combined with the discursive resources that were developed in the communities from the entry of multinationals. Far from usurping natural resources, transnationals took advantage of discursive contexts to implement business models that were complemented by the learning of migrants on their journey through the United States.

In this way, entrepreneurship in Xilitla reduces the differences between multinationals and local SMEs to build discourses around cooperation, commitment and innovation embodied in the production of organic coffee and ecotourism promotion that make Xilitla a magical entrepreneurial town.

The process that involved the transformation of a migrant locality to a trading community meant the change of social representations which consisted of symbols of subsistence outside the region. Once in the United States, the migrants learned habits of consumption that influenced their decisions to return to Xilitla to implement the trade models they learned. Their arrival in Xilitla was supported by discursive fields around which they represented progress for the community not only in economic terms, but also in social aspects. In this sense, the investment of seed capital was complemented by the business development policies that the federal and local governments were in charge of disseminating among those who could value and responsibly use the entrusted capital. Finally, the arrival of foreign capital complemented the entrepreneurial dynamics of Xilitla since it allowed the construction of hotel infrastructure that empowered the community as a magical town, ecotourist and coffee grower. 
However, the explanation regarding the relationship between transnationals and SMEs in the face of droughts and floods is pending. Indeed, climate change seems to be the potential threat to the region since its activities depend directly on the equitable distribution of water. An imbalance in the allocation of water between transnationals, SMEs and communities would affect the production, distribution and sale models.

The Social Reliability Theory (SRT) indicates that unlike the contexts of life satisfaction in which trust and commitment are its main axes, in a context of uncertainty, entrepreneurship underlies as a solidary response in the face of ecological, economic or social misfortune. Precisely, the representations, habitus, fields, capitals and entrepreneurial capacities in Xilitla seem to converge more with the entrepreneurial stability model in reference to the uncertainty model.

It is therefore essential to promote social reliability among the actors involved in the local development of Xilitla. However, the participation of the local and federal government would not only be reduced to the allocation of seed capital, but now its function would consist of the organization of a network of freedoms, opportunities, capacities and responsibilities translated into a system of governance. Transparency in the allocation of financial resources would not be enough if, in the face of a contingency or catastrophe, the authorities sought the well-being of one sector to the detriment of another. A system of government is required in which decisions are no longer discretionary and conform to the principles of Sustainable Local Development. The governance of natural resources oriented towards local development supposes the construction of a public agenda in which the central issues are related to social reliability and entrepreneurship.

\section{Conclusions}

Entrepreneurship involves the implementation of policies to promote production in communities and localities that establish strategic alliances with transnationals through SMEs. As i itself, is the result of a process of social representation in which its core consists of values, skills and knowledge of enterprise transmitted from generation to generation. It is the experiences in their stay as migrants in the United States that complement the social representations and reveal habitus inherited in Xilitla and acquired in the United States.

It is in the acquired habitus from which discursive fields of power are derived that made former migrant's leaders since they are considered by the community as examples to follow in terms of entrepreneurship. Words such as; "marketing", "business", "commitment" or "capabilities" have been incorporated into the community as symbols of discursive power and meanings of commerce. In addition to the discursive fields, the training of microentrepreneurs was carried out based on trust and cooperation that resulted in strategic alliances of the community with transnational corporations.

In short, the town of Xilitla acquired enough business skills to promote itself as a magical town, ecotourist and coffee grower. Unci its image as migrant was transformed into an image of business, the community and its authorities are faced with the possibility of addressing environmental contingencies trusteeing local development.

\section{Acknowledgement}

We would like to thank the journal's editor and the anonymous reviewers for their positive feedback and suggestions for the improvement of this article

\section{References}

[1] World Health Organization. Statistic for coronavirus SARS CoV-2 and Covid-19 disease in the wrld. WHO

[2] Panamerican Health Organization. Statistic coronavirus SARS CoV-2 and Covid-19 disease in the Americas. PAHO

[3] Adenike, A. (2011). Organization climate as a predictor of employee job satisfaction. Business Intelligence Journal. 4, 151-166

[4] Anwar, F. and Norulkamar, U. (2012). Mediating role of organizational commitment among leadership and employee outcomes, and empirical evidence from telecom sector. Processing International Seminar on Industrial Engineering and Management 2, 116-161

[5] Arnau, L. and Montané, J. (2010). Contributions on the conceptual relationship between attitude and competence, from the theory of change of attitudes. Journal of Rese arch in Educational Psychology. 8, 1283-1302

[6] Basta, R., Cavalleri, M., Fink, T., López, X., Maiola , F., Stancanelli, M., and Vdovsov , L. $\quad$ (2012). An approach to the theoretical methodological production of Pierre Bourdieau. His influence on Argentine Social Work. Public Square, 8, 39-51

[7] Borjas, L. (2010). Entrepreneurship from social representations: the case of Venezuela. Social Sciences, 5, 149-165

[8] Bourdieu, P. (2011). The strategies of social reproduction. Mexico: 21st century 
[9] Cardon, M. Gregoire, D., Stevens, C. and Patel, P. (2013). Measuring entrepreneurial passion: conceptual foundations and scale validation. Journal of Business Venturing, 28, 373-396

[10] Capdevielle, J. (2011). The concept of habitus. Anduli. Andalusian Journal of Social Sciences, 10, $31-$

[11] Berdecia, Z., Gonzalez, J. and Carrasquillo, C. (2012). Leadership Styles for Organizational Success: Multiple Case Studies in Companies. Journal of Advanced Leadership Studies, 1, 21-32

[12] Castro, M. and Martins, M. (2010). The relationships between organizational climate and employee satisfaction in information and technology organization. Tydskriff vir Bredyfsielkunde. 36, 1-9

[13] Castel, G. and Freundlich, F. (2010). Perceptions of cooperative members and non-members on job satisfaction. Revesco. 103, 33-58

[14] Castro, M. (2011). Linguistic habit and right to information in the medical field. Mexican Journal of Sociology, 73, 231-259

[15] Caykoylu, S., Egri , C., Havlovic , S. and Bradley, C. (2011). Key organizational commitment antecedents for nurses, paramedical professionals and non-clinical staff. Journal of Health Organization and Management. 25, 7-33

[16] Celik, M., Turunc, O. and Begenirbas, M. (2011). The role of organizational trust, Burnout and interpersonal deviance for achieving organizational performance. International Journal of Business and Management Studies. 3, 179-190

[17] Chiang, M., Méndez, G. and Sánchez, G. (2010). How job satisfaction influences performance: retail's company case. Theories Magazine. 19, 21-36

[18] Chinchilla, N. Cruz, M. (2010). Diversity and business paradigms: a new approach. Business and Humanism Magazine, 14, 47-7

[19] Coronel, A. (2010). Training of human capital for a development investment. Eureka, 7, 71-76

[20] Cuesta, A. (2012). Integrated model of human and knowledge management: an application technology. Revista Venezolana of Management, 57, 86-98

[21] Danes, S. and Juyoung, J. (2013). Copreneural identity development during new venture creation. Journal of Family Business Management, 3, 45-61

[22] Diaz, C., Hernández, R. and Roldan, J. (2012). A structural model of the antecedents to entrepreneurial capacity. International Small Business Journal, 30, 850-872

[23] Diaz, S. (2013). The human in the Theory of Organizations. Managerial vision, 12, 45-57

[24] Figeiredo, H., Grau, E., Gil, P. and Garcia, J. (2012). Work burn syndrome and job satisfaction in nursing professionals. Psocthema, 24, 271-276

[25] Fortich, M. and Moreno, Á. (2012). Elements of field theory. VerbaIuris, 27, 47-62

[26] Fuentes, F. and Sánchez, S. (2010). Analysis of the entrepreneurial profile: a gender Economics Studies, 28, 1-28

[27] Galindo, R. and Echavarría, M. (2011). Diagnosis of the entrepreneurial culture in the Antioquia engineering school. Journal of the School of Engineering of Antioquia, 15, 85-94

[28] García, A. (2011). Micro spatial conflicts and political habitus of anti-hegemonic groups. Nomads, 3, 120

[29] Gargallo, A. (2010). Perceptions of cooperative members and non-members on job satisfaction. Revesco, 103, 33-58

[30] Gaxiola, J., Frías, M., Hurtado, M., Salcido, L. and Figueroa, M. (2011). Validation of the resilience inventory (IRES) in a sample from northeastern Mexico. Teaching and Research in Psychology. 16, 73-83

[31] Giddens, A. (2011). The society Constitution. Bases for the Restructuring Theory. Buenos Aires: AmorrortuEditores.

[32] Gonzalez, E. and Perez, E. (2012). Labor conditions and professional burnout in health workers. Alternatives in Psychology, 27, 8-22

[33] González, F., Sánchez, S. and López, T. (2011). Job satisfaction as a critical factor for quality. Studies and Perspectives in Tourism, 20, 1047-1068

[34] Guillén, M. Lleó, A. and Perles, G. (2011). Rethinking trust as a critical factor in organizational management. Management Notebooks. 11. 33-47

[35] Hallak, R., Brown, G. and Lindsay, N. (2012). The place identity performance relationships among tourism entrepreneurs: a structural equation modeling analysis. Tourism Management, 33, 143-154

[36] Hazlina, N., Mohd, A. and Rohaida, S. (2012). Nurturing intrapreneurship to enhance job performance: the role of pro-intrapreneurship organizational architecture. Journal of Innovation Management in Small \& Medium Enterprises, 9 9/1

[37] Joignant, A. (2012). Habitus, field and capital. Elements for a general theory of political capital. Mexican Journal of Sociology, 74, 587-618

[38] Jyoti, J. and Jyoti S. (2011). Factors affecting orientation and satisfaction of women entrepreneurs in rural India. Annals of Innovation Entrepreneurships, 2, 1-8 
[39] Lanier, J. (2012). Leadership and organizational theory dynamics between middle market private equity forms and the portfolio companies they control. Journal of Practical Consulting, 4, 6-21

[40] Long, H. (2013). The relationships among learning orientation, market orientation, entrepreneurial orientation, and firm performance. Management Review, 20, 37-46

[41] López, Á., Vázquez, P. and Montes, C. (2010). Mobbing: psychosocial antecedents and consequences on job satisfaction. Latin American Journal of Psychology, 42, 215-224

[42] Manning, A. (2010). Development of the psychological climate scale for small business. Journal of New Business Ideas \& Trends. 8, 50-63

[43] Martínez, E. (2013). Kabylia: the problematic genesis of the concept of habitus. Mexican Journal of Sociology, 75, 125-131

[44] Mendoza, M., Orgambídez, A. and Carrasco, A. (2010). Orientation of total quality, job satisfaction, communication and commitment in rural tourism establishments. Journal of tourism and cultural heritage. 8 , $351-361$

[45] Molero, F., Recio, P., and Cuadrado, I. (2010). Transformational and Transactional Leadership: An Analysis of the Factor Structure of the Multifactor Leardership Questionnaire (MLQ). Psicothema. 22, 495501

[46] Morales, A., Ariza, A. and Muñiz, N. (2012). The social entrepreneur and e-empowerment of social networks. Revista de Economía Pública, Social y Cooperativa, 75, 152-177

[47] Moreno, M., Ríos, L., Canto, J., García, J. and Perles, F. (2010). Job satisfaction and burnout in lowskilled jobs: differences between the sexes in the immigrant population. Journal of Work and Organization Psychology, 26, 255-265

[48] Omar, A. (2010). Transformative leadership and job satisfaction: the role of trust in the supervisor. Liberabit. 17, 129-137

[49] Rante, Y. and Warokka, A. (2013). The interrelative nexus of indigenous economic growth and small business development: do local culture, government role, and entrepreneurial behavior play the role? Journal of Innovation Management in Small \& Medium Enterprises. 19, 1-19

[50] Ríos, M., Téllez, M. and Ferrer, J. (2010). Empowerment as a predictor of organizational commitment in SMEs. Accounting and Administration. 231, 103-125

[51] Rodríguez, A., Retamal, R., Lizana, J. and Cornejo, F. (2011). Climate and job satisfaction as predictors of performance: in a Chilean state organization. Health and Society. 2, 219-234

[52] Rojas, R., García, V. and García, E. (2011). The influence on corporate entrepreneurship of technological variables. Industrial management \& Data System, 111, 984-1005

[53] Sen, A. (2011). The idea of justice. Cambridge: Harvard University Press

[54] Sobrados, L. and Fernández, E. (2010). Entrepreneurial skills and development of entrepreneurship in educational centers. Education XXI, 13, 15-38

[55] Tayo, E. and Adeyemi, A. (2012). Job involvement \& organizational commitment as determinants of job performance among resource center personal. European Journal of Globalization and Development Research. 5, 301-313

[56] Vargas, J. (2011). Work organization and job satisfaction: a case study in the footwear industry. Nova Scientia Electronic Magazine. 4, 172-204

[57] Vargas, J. and Mota, C. (2013). Social management for gender equality in organizations. International Journal of Good Concert, 8, 130-47

[58] Vargas, J. (2013). Organizations as brains to generate social capital. International Journal of Good Conscience, 8, 82-93

[59] Vargas, M. and Arenas, M. (2012). Entrepreneurial competences in psychopedagogy students of the Pedagogical and Technological University of Colombia. Journal of Advanced Leadership Studies, 1, 25-30

[60] Vera, L., Madrazo, S. and García, L. (2011). Sources of job satisfaction in young salaried peasants.Conitec, 77, 1281-1306

[61] Yáñez, R., Arenas, M. and Ripoll, M. (2010). The impact of interpersonal relationships on job satisfaction. Liberabit. 16, 193-202

[62] Yuangion, Y. (2011). The impact of strong ties on entrepreneurial intention. An empirical study based on the mediating role of self-efficacy. Journal Entrepreneurship, 3, 147-158

[63] Zampetakis, L. and Moustakis, V. (2013). Entrepreneurial behavior in the Grekk public sector. Emerald, 13,

[64] Garza J, Hernandez, T, Coronado O, Hernandez J, Bermudez G, Garcia C. Speciication a modelo f sustainable justice. PalArch, 2021; 17 (4), 1-19

[65] Garcia C, Bustos J, Juarez M, Sandoval F. Contraste de un modelo de gobernanza de sustentabilidad hídrica. Revista Ciencia Política, 2021; 15 (1), 1-16 
[66] Garza J, Hernandez T, Carreon J, Espinoza F, Garcia C. contraste de un modelo de los determinantes de la instancia turística en la era Covid-19: Implicaciones para la bioseguridad. Turismo \& Patrimonio, 2021; 16 (1), 71-84

[67] Sandoval F, Bustos J, Juarez M, Garcia C. specification a model for study of social work sustainable. Educazonia, 2021; 13 (1), 343-353

[68] Alvarado S, Carreon J, Garcia C. Modeling of the mobility habitus in the public transport system with low CO2 emission mechanics in the center of Mexico. Advances in Mechanics, 2021; 9 (2), $82-95$

[69] Hernandez T, Carreon J, Garcia C. Reingenering in the entrepreneurship of the coffee industry and toruism in the central Mexico. Journal Advances, 2021; 9 (2), 63-81

[70] Bustos J, Garcia C, Carreon J, Hernandez J Juarez M. Perception of risk among university students before the spread of the Covid-19. Medical Research Crhonics. 2021; 8 (3), 1-9

[71] Sandoval F, Molina H, Garcia C. Metanalytical netwprk retrospective of public transport and its effect of the governance of heath. International Journal in Social Science, 2021; 9 (1), 8-18

[72] Molina R, Coronado O, Garcia C, Quiroz C. Contrast a model security perception in the Covid-19 era. Journal of Community Medicine and Public Health Care. 2021; 8 (1), 77-85

[73] Garcia C, Bustos J, Juarez M. Biosafety in the millennial generation in the Covid-19 era. Environments, 2021; 8 (1), 2-5

[74] Garcia C. percepción de la seguridad publica en la era pos Covid-19. Proyeccion Soial, 4 (1), 45-54

[75] Bustos J, Juarez M, Garcia C, Sandoval F. Determinantes psicosociales del turismo en la era Covid19. Turismo \& Desarrollo Local, 2021; 29 (1), 1-23

[76] Garcia C, Bustos J, Sandoval F, Quiroz C. Specification a model for study of perceived risk. Reget, 2020; 24 (43), 1-8

[77] Garcia C, Carreon J, Bustos J, Hernandez J. Percepcion del emprendimiento caficultor en la región huasteca, centro de Mexico. Activos, 2020; 18 (1), 239-270

[78] Bustos J, Aldana W, Hernandez T, Garcia C. Una revisión de hallazgos en torno al desarrollo local. Eureka, 2020; 17 (1), 141-161

[79] Bustos J, Juarez M, Garcia C, Quiroz C, Rosas F, Molina R. Confirmacion factorial confirmatoria de percepción de seguridad. Eureka, 17 (1), 85-95

[80] Carreon J, Bustos J, Juarez M, Hernandez J, Sanchez A, Garcia C. Coffee entrepreneurship during Covid-19. Publicaciones e Investigaciones, 2020; 14 (1), 1-12

[81] Bustos J, Garcia C, Juarez M. Percepcion de seguridad frente a la Covid-19. Sin Frontera, $2020 ; 13$ (32), 1-26

[82] Molina H, Juarez M, Bustos J, Hernandez J, Castro M, Garcia C. Sturctural factor exploring sustainable perception. Sin Frontera, 2020; 13 (32), 1-23

[83] Garcia C. Specification a model for study of perception risk. Educazonia 